Brit. J. vener. Dis. (1959), 35, 208.

\title{
REACTIONS TO ANTIBIOTICS*† THEIR IMPORTANCE IN VENEREOLOGY
}

\author{
BY
}

\author{
R. R. WILLCOX
}

St. Mary's Hospital, London, W.2

It is now 17 years since antibiotics were first introduced to bring about a revolution in the treatment of the venereal diseases. Their particular feature from the outset was their relative freedom from serious side-effects as compared with the exfoliative dermatitis, agranulocytosis, encephalopathy, stomatitis, and crystalluria which were not uncommon when the principal weapons against these diseases were the organic arsenical, bismuth, and sulphonamide drugs.

Even with the first antibiotic-penicillin-some patients exhibited urticaria, but this allergic response was considered relatively trivial in comparison with the more serious complications listed above. The newer antibiotics (such as streptomycin with its toxic action on the eighth nerve, and the tetracyclines leading to superinfection with staphylococci and fungi), brought their own problems. With the passage of time, some of the groups of organisms which were originally susceptible to antibiotics began to shew a higher proportion of resistant strains than formerly, and allergic reactions also became more serious. The object of this paper is to indicate the impact that these events have so far had on venereology.

The various types of antibiotic reactions may be classified as follows:

(1) Toxic REACTIONS
(a) Systemic

(b) Local

(2) Microbiogenic Sequelae
(a) Microbial lysis
(b) Microbial overgrowth
(c) Microbial resistance
(d) Other microbiogenic effects

\footnotetext{
* Received for publication March 31, 1959.

+ Paper read to the Richmond Division of the British Medical Association on February 20, 1959.
}

(3) Allergic Reactions

(a) Skin reactions

(b) Anaphylactic reactions.

\section{(1) Toxic Reactions}

(a) Systemic.-The first antibiotic-penicillin-has been and still is remarkable in its freedom from truly toxic effects. Experience in humans and in animals has shewn that the toxic doses far exceed those required to obtain therapeutic effect. Indeed it has been calculated that the 50 per cent. lethal single dose in man lies in the range of $25-150$ million units, depending on the preparation used (Guthe, Idsöe, and Willcox, 1958).

Streptomycin, on the other hand, was found quite early to have a selective toxic action on the eighth nerve, although cases shewing this complication had usually already been treated with multiple daily doses for considerable periods of time for some serious disorder such as tuberculous meningitis. Toxic effects can occur, however, from relatively small dosage, and Cawthorne and Ranger (1957) recently described fourteen cases in which $1 \mathrm{~g}$. daily to a total of only $20 \mathrm{~g}$. or less had been used.

In venereology streptomycin is usually given only in small amounts. Except for the relatively very rare condition of granuloma inguinale, in which 10 to $20 \mathrm{~g}$. may be given over 5-10 days, this antibiotic is usually used (in combination with sulphonamides) for one, or at the most, two or three injections, for non-gonococcal urethritis. Toxic reactions are very seldom encountered. More recently, dihydrostreptomycin has been shewn to be particularly toxic to the eighth nerve, even in small doses of 1 to $2 \mathrm{~g}$., but little experience of this has been reported from the venereal disease clinics.

The tetracyclines have also been relatively free of toxic effects, but some of the other antibiotics may occasionally evoke serious signs of toxicity. Chloramphenicol is a striking example, with its well-known depressant effects upon the haemopoietic system. 
Febrile reactions may follow the use of Amphotericin B (Rubin, Lehan, FitzPatrick, and Furcolow, 1958), and some antibiotics (e.g. Ristocetin A) may be nephrotoxic (Hwang, Primack, Stein, and Richards, 1958). Other effects include purpuric skin rashes and liver necrosis which have been reported following the use of novobiocin (Bridges, Berendes, and Good, 1957).

(b) Local.- - These include venous thrombosis when antibiotics are given intravenously and muscle necrosis when they are given intramuscularly, e.g. Vancomycin (Romansky, Limson, and Hawkins, 1957) and Ristocetin (Anderson, Worth, Harris, and Chen, 1957). Local urticaria at the site of injection and cold abscess resulting from the Arthus phenomenon are not considered in this group as these reactions are allergic in nature. Few local reactions have been experienced with crystalline penicillin $\mathbf{G}$, aqueous procaine penicillin, procaine penicillin in oil with aluminium monostearate, or streptomycin. On the other hand, with the newer repository penicillins-benzathine penicillin and benethamine penicillin-local pain was much more frequent, but this problem now has happily been largely overcome.

There is an obvious need for a repository type of tetracycline which can be given intramuscularly when an alternative antibiotic to penicillin is required. Such a preparation is being developed, and a dose of $500 \mathrm{mg}$. ( $4 \mathrm{ml}$.) can produce a concentration in the blood sufficient to cure gonorrhoea, but at present it too may evoke painful local reactions.

\section{(2) Microbiogenic Sequelae}

(a) Microbial Lysis.-The signs and symptons of certain infections are sometimes exacerbated after treatment with a powerful antimicrobial drug. This is usually ascribed to the release of noxious substances consequent upon the death of the responsible organisms, to which the name therapeutic shock or Jarisch-Herxheimer reaction has been given.

Only in syphilis is this reaction of practical importance. In early adult syphilis it may occur in 80 per cent. or more of cases and is indicated by a rise in temperature and sometimes by the intensification of the rash. Such a phenomenon, although like influenza it may be temporarily incapacitating, is not of serious consequence and it is seldom necessary to interrupt the treatment.

In early congenital syphilis therapeutic shock may apparently sometimes prove fatal in debilitated babies, and focal Herxheimer reactions may occa- sionally prove serious and even fatal in neurosyphilis, cardiovascular syphilis, and gummatous late syphilis, when oedema occurring around the syphilitic process may involve some vital structure. In neurosyphilis, for example, convulsions, exacerbated psychosis, rapid paretic deterioration, or quickly advancing optic atrophy have been observed. In cardiovascular syphilis, signs of coronary occlusion may become apparent.

The Herxheimer reaction may follow the use of any powerful treponemacidal drug, and it was wellknown, of course, in the arsenical era. There is little indication that large doses are more apt than small doses to cause therapeutic shock, which appears to be an "all or none" phenomenon. Many physicians treating late syphilis with penicillin begin with small doses, but this is unlikely to prevent a Herxheimer reaction.

Another possible consequence of therapy and microbial lysis is therapeutic paradox, in which, in spite or because of too rapid healing of lesions, the patient becomes worse from the effects of the resultant scarring process. Possible examples include the occurrence of or an increase in aortic regurgitation following the treatment of syphilitic aortitis; ascites and liver failure occurring after too rapid a shrinkage of a gummatous liver; and an increasing paretic deterioration in spite of the achievement of a normal cerebrospinal fluid. Reported cases of therapeutic paradox in syphilis are very few, and they are seldom unequivocal in so far as some may have resulted not from paradox but from insufficient treatment.

An example of therapeutic paradox in another field is that reported by Popper (1957) from South Africa-namely antibiotic deafness. When large doses of antibiotics are given for middle ear disease, the inflammation is rapidly averted and the retained fluid in the middle ear becomes sterile, but the capillaries are not stimulated to dilate and absorb this fluid. Deafness may then follow and drainage may be required.

(b) Microbial Overgrowth.-This is a problem of considerable magnitude and is intimately concerned with the companion problem of microbial resistance, for it is the antibiotic-resistant organisms which gain a footing and multiply in the host when their antibiotic-sensitive competitors have been eliminated by therapy.

The principal factory of antibiotic-resistant organisms-particularly staphylococci-is the hospital, where antibiotic treatment is in continual use and where in-patients may act as living test-tubes in 
the production of resistant bacteria. In primitive populations there may only be a few strains of penicillin-resistant staphylococci (Rountree, 1956). In hospitals not only do the skin and nares of the patients shew penicillin-resistant strains, but also the dust, and therefore the air (Gould, 1958). Indeed the conditions found in hospitals and in hospitalworkers are very similar to those in the actual laboratories where penicillin is made.

In hospitals the resistance of staphylococci to antibiotics is related to the degree of usage of the antibiotic concerned, and therefore to the antibiotic in current favour (Hinton and Orr, 1957).

Once present in the ward, the antibiotic-resistant staphylococci can become a danger in two ways:

(i) By super-infection of patients already treated for some other condition by antibiotics;

(ii) By cross-infection of other patients in the ward who may or may not have been treated by antibiotics.

It is not always possible to determine which type of infection has occurred.

Staphylococcal pneumonias and urinary and wound infections have become of serious concern in medical, paediatric, surgical, and gynaecological wards (Shooter, Griffiths, Cook, and Williams, 1957), and minor staphylococcal infections in wards can no longer be taken lightly (Beaven and Burry, 1956). Finland and Jones (1956) who made a spot survey of 1,172 patients in hospital, found 181 persons with staphylococcal infections, 113 of whom had acquired their infection while in hospital.

Another dangerous form of super-infection is staphylococcal enteritis, which most commonly arises following the oral administration of antibiotics through microbial overgrowth in a bacterial "vacuum" which is due to the partial sterilization of the bowel. It may sometimes result from antibioticresistant organisms in the mouth and throat (Fairlie and Kendall, 1953) after the parenteral administration of penicillin or streptomycin. Even as early as 1955 some 56 fatal cases of staphylococcal enteritis had been reported in the literature (Thaysen, Eriksen, Fischermann, and Knudsen, 1955).

Although a number of patients and hospital staff may become carriers of resistant staphylococci, it is fortunate that on leaving hospital, many such persons tend to lose them within a few weeks as they become diluted in the general population.

Venereal disease patients to-day are seldom admitted to hospital, and are therefore unlikely to become super-infected or to cause cross-infection with resistant staphylococci in this way. They are at risk, however, from bacterial overgrowth, especially when taking the tetracyclines (with or without oleandomycin), spiramycin, or other orally administered antibiotics (e.g. phenoxymethyl penicillin) for non-gonococcal or gonococcal urethritis. Even with the former, however, the usual course is only $1 \mathrm{~g}$. daily for 4 to 6 days, and although "antibiotic diarrhoea" sometimes occurs (and usually ceases fairly quickly on discontinuation of therapy) the author has not yet had to admit a patient to hospital on account of staphylococcal enteritis.

A more common problem is that of overgrowth by Candida albicans, which has been reported after antibiotic therapy in a number of sites, including the mouth, the respiratory, intestinal, and renal tracts, and the skin. Dissemination has occasionally occurred and even endocarditis has been recorded. The commonest symptom is that of rectal burning and irritation, which is more common after the use of the tetracycline antibiotics than after penicillin. As both penicillin and tetracycline are capable of enhancing the growth of Candida albicans, the explanation probably lies in the fact that coliforms suppress the growth of monilia and these bacteria are less affected by penicillin than by the tetracyclines.

Other fungus infections may thrive during antibiotic therapy. Flares of athlete's foot and tinea cruris are well known. Rarer fungus infections such as aspergillosis and geotrichosis of the lungs have also been reported (Hussar and Holley, 1954).

(c) Microbial Resistance.-Venereologists who worked in the sulphonamide era have never forgotten how these drugs, which initially were 85-90 per cent. successful in gonorrhoea, slowly deteriorated to uselessness as resistant strains of gonococci took over the field.

Fortunately, as far as syphilis is concerned, there are as yet no signs that the treponeme is developing "resistance" to penicillin. But T. pallidum is one of the organisms most sensitive to penicillin and only low serum concentrations (above 0.03 unit per ml.) are required-although it is important that the treponeme is subjected to this level or above for a considerable period of time. Not so with gonorrhoea, however, in which progressively higher failure rates are currently being reported in spite of the use of increasing dosages of penicillin. 
For example, at St. Mary's Hospital, London, the failure rate in 1954 with as little as 0.3 mega unit procaine penicillin with aluminium monostearate (PAM) was only 4.6 per cent. In 1956-1957 it had risen to 17.9 per cent. with $0 \cdot 6-1 \cdot 2$ mega unit (Table I).

\section{TABLE I}

RESULTS OF TREATMENT OF GONORRHOEA WITH PAM IN LONDON, 1952-1957

\begin{tabular}{c|c|c|c|c|c|c}
\hline Year & $\begin{array}{c}\text { Dose } \\
\text { (mega } \\
\text { units) }\end{array}$ & $\begin{array}{c}\text { No. of } \\
\text { Cases } \\
\text { Treated }\end{array}$ & $\begin{array}{c}\text { No. } \\
\text { Followed- } \\
\text { up }\end{array}$ & $\begin{array}{c}\text { No. of } \\
\text { Failures }\end{array}$ & $\begin{array}{c}\text { Re- } \\
\text { infections }\end{array}$ & $\begin{array}{c}\text { Per cent. } \\
\text { Failing } \\
\text { of those } \\
\text { Followed }\end{array}$ \\
\hline 1952 & $0 \cdot 15$ & 223 & 200 & 18 & 42 & $9 \cdot 0$ \\
1954 & $0 \cdot 3$ & 226 & 194 & 9 & 22 & $4 \cdot 6$ \\
1956 & 0.6 & 226 & 190 & 34 & 23 & 17.9 \\
1957 & $1 \cdot 2$ & 44 & 39 & 7 & 15 & 17.9 \\
\hline Total & & 719 & 623 & 68 & 102 & 10.9 \\
\hline
\end{tabular}

With benzathine penicillin, which provides a lower peak serum level, although its action is more prolonged than that of PAM, failure rates of $30 \cdot 3$ per cent. were noted in 1957 with doses as high as $1 \cdot 2$ mega units (Table II).

TABLE II

RESULTS OF TREATMENT OF GONORRHOEA WITH BENZATHINE PENICILLIN IN LONDON, 1957

\begin{tabular}{c|c|c|c|c|c}
\hline $\begin{array}{c}\text { Dose } \\
\text { (mega } \\
\text { units) }\end{array}$ & $\begin{array}{c}\text { No. of } \\
\text { Cases } \\
\text { Treated }\end{array}$ & $\begin{array}{c}\text { No. } \\
\text { Followed- } \\
\text { up }\end{array}$ & $\begin{array}{c}\text { No. of } \\
\text { Failures }\end{array}$ & $\begin{array}{c}\text { Re- } \\
\text { infections }\end{array}$ & $\begin{array}{c}\text { Per cent. } \\
\text { Failing } \\
\text { of those } \\
\text { Followed }\end{array}$ \\
\hline $\begin{array}{c}0 \cdot 3 \\
0 \cdot 6\end{array}$ & $\begin{array}{c}98 \\
125\end{array}$ & 76 & 24 & 3 & $31 \cdot 6$ \\
$1 \cdot 2$ & 41 & 33 & 21 & 3 & $22 \cdot 8$ \\
\hline Total & 264 & 201 & 55 & 6 & $27 \cdot 4$ \\
\hline
\end{tabular}

Similar experiences are being noted in other parts of Britain (e.g. Birmingham-Knight, 1958) and also in Europe (e.g. Vienna-Streitmann and Krassnigg, 1957 ), although the process has not yet advanced as much as in London. In Birmingham the failure rate has increased from 3 to $7 \cdot 3$ per cent. in 3 years, and in Vienna from 0.25 to 4.4 per cent.

The increasing failure rates with penicillin are related to a reduced sensitivity of the organisms to the antibiotic. For example Reyn, Korner, and Bentzon (1958), in Copenhagen, have shewn a definite lowering in the sensitivity of the gonococcus by comparing strains isolated in 1944 and in 1957. In London, Curtis and Wilkinson (1958) noted that 19.5 per cent. of recent strains of gonococci had a sensitivity range as low as $0 \cdot 125-0.5$ unit penicillin per $\mathrm{ml}$. and that treatment failures occurred predominantly in patients in whom the sensitivity tests had shewn low readings.
This situation has largely come about with the use of repository penicillins the peak serum levels of which are relatively low. Such penicillin preparations (penicillin in oil and beeswax, procaine penicillin $G$ in oil with aluminium monostearate, benzathine penicillin, and benethamine penicillin) have been those suitable for the out-patient treatment of syphilis and, as long as they worked well in gonorrhoea also, it has been administratively easier to use the same preparation for the two diseases. To-day most authors who have studied the subject (e.g. Reyn and others, 1958; Curtis and Wilkinson, 1958; Landman, Phillips, and Friend, 1958; Willcox, 1958; Cradock-Watson, Shooter, and Nicol, 1958; Schamberg, Kalodner, and Lentz, 1958) are agreed that the resistance problem will increase if penicillin preparations giving low peaks continue to be used. A higher peak is necessary and aqueous procaine penicillin in single or multiple doses of $0 \cdot 6-1 \cdot 2$ mega units or more is to-day generally preferred.

In England we have always relied mainly upon penicillin for the treatment of gonorrhoea. In France the possibility of masking simultaneously acquired syphilis by giving penicillin for gonorrhoea was taken more seriously and for this reason a regime consisting of single injections of $0 \cdot 5-1 \cdot 0 \mathrm{~g}$. streptomycin has for many years been in general use for gonorrhoea in that country. Exactly the same problem is now present there also with streptomycin, increasing failure rates being accompanied by increasing dosage (Durel, 1958).

This serious situation of deteriorating results is accompanied by a substantial increase in the attack rate of gonorrhoea. In the clinics of England and Wales in 1958, the number of cases of gonorrhoea rose sharply to 27,887 from 20,388 in $1956,17,845$ in 1955 , and 17,536 in 1954 (Table III); a similar situation obtains in many other countries.

TABLE III

NUMBER OF CASES OF GONORRHOEA ATTENDING THE CLINICS OF ENGLAND AND WALES, BY SEX, 1938-1958

\begin{tabular}{cc|c|c|c}
\hline \multicolumn{2}{c|}{ Year } & Males & Females & Total \\
\hline 1938 & $\ldots$ & 27,947 & 7,746 & 35,693 \\
1946 & $\cdots$ & 36,912 & 10,431 & 47,343 \\
1954 & $\cdots$ & 13,962 & 3,574 & 17,536 \\
1955 & $\cdots$ & 14,079 & 3,766 & 17,845 \\
1956 & $\ldots$ & 16,379 & 4,011 & 20,388 \\
1957 & $\cdots$ & 19,620 & 4,761 & 24,381 \\
1958 & $\cdots$ & 22,398 & 5,489 & 27,887 \\
\hline
\end{tabular}

The increase in the attack rate is occurring mainly in the big cities, and not in the rural areas in many of which the prevalence of the disease continues to decline. 
What this means in respect of some of the large VD clinics is shown in Table IV for St. Mary's Hospital, London, and the General Hospital, Birmingham, where within 3 to 4 years the case load has more than doubled.

TABLE IV

INCREASE IN NEW MALE CASES OF GONORRHOEA IN LONDON AND BIRMINGHAM, 1955-58

\begin{tabular}{cc|c|c}
\hline Year & $\begin{array}{c}\text { St. Mary's Hospital, } \\
\text { London }\end{array}$ & $\begin{array}{c}\text { Birmingham } \\
\text { (Knight, 1958) }\end{array}$ \\
\hline 1955 & $\cdots$ & 1,194 & 444 \\
1956 & $\cdots$ & 1,698 & 858 \\
1957 & $\cdots$ & 2,228 & 1,063 \\
1958 & $\cdots$ & 2,661 & NR. \\
\hline
\end{tabular}

Various factors, other than lessened sensitivity of the gonococcus to antibiotics, are of course responsible for this substantial increase in the attack rate. In the United Kingdom there is the continuing large-scale immigration from the West Indies, which numerous authors (e.g. Laird, 1958; Knight, 1958; Willcox, 1958b) have indicated as being responsible for approximately one half of the new gonococcal infections encountered in the areas in which these immigrants reside.

It has been noted (Willcox, 1958b; Knight, 1958) that the failure rate in West Indian Negroes is almost double that in other groups, even when apparent re-infections are allowed for. The view has been advanced that the lessened sensitivity of the gonococcus is being developed more quickly in this ethnic minority (and their mainly prostitute consorts) by the oft repeated exposure of the gonococcus to the low levels of penicillin carried by this group as a whole as a result of their repeated treatments for the disease (Willcox, 1958b).

(d) Other Microbiogenic Effects.-These include signs of avitaminosis arising from disturbances of the metabolism of the vitamin B complex in the gastrointestinal tract (sore tongue, etc.). It is not fully understood whether this arises from local irritation from orally administered antibiotics, or in the bowel, or, as seems more likely, as a result of bacterial overgrowth.

For completeness, the masking of diseases other than that for which the treatment is intended, and the passage of other diseases by the treatment itself must be included under this heading.

Syphilis may be masked by the relatively small doses of penicillin given for gonorrhoea. Venereologists were alive to this possibility from the first introduction of penicillin therapy and it was the principal reason why for some years the doses of repository penicillin were kept at the lowest level consistent with clinical efficacy. Indeed this very policy has perhaps contributed more than any other to the "resistance" situation which exists to-day. As the years unfolded the question of masking of syphilis proved a bugbear. Either the disease was aborted completely, or it declared itself (clinically or by serum test) within the usual over-all incubation period of 3 months. In fact, the disease was usually cured in the incubation period and the enormous decline in the numbers of cases of early syphilis (a fall of over 95 per cent. in the clinics of England and Wales between 1946 and 1956) has probably been achieved because of the enormous use of penicillin for gonorrhoea and other diseases which cut it off in this way.

Diseases which may be transmitted with injections of antibiotics include organisms responsible for local sepsis (rare as antibiotics are largely selfsterilizing), and syringe-transmitted hepatitis (rare now that adequate sterilization of syringes is general and, in any event, uncommon after intramuscular injections). There is also the possibility of provoking the clinical manifestations of poliomyelitis when injections are given to persons who are incubating this disease.

\section{(3) Allergic Reactions}

While toxic manifestations occur as a result of the normal pharmacological action on a quantitative basis in every person exposed to the drug, allergic $r$ zactions result from a qualitative hypersensitivity of the individual. Of the antibiotics causing allergy, penicillin is most often responsible and, as in the case of other allergens, may evoke two different allergic responses-skin reactions and anaphylactic reactions-depending on the preponderance of the type of antibody produced.

(a) Skin Reactions.-These include contact dermatitis in those exposed locally to the antibiotic; generalized dermatitis which may follow systemic or local exposure (and may occasionally be fatal from pneumonia or other causes); and trichophytid-like reactions characteristically localized to the groins, interdigital spaces, palms, and soles. Cross-sensitivity from a previous fungus infection may be responsible for some of these cases.

The next important group comprises urticaria, angio-oedema, and serum-sickness-like reactions. Urticaria, which is frequently mild and is usually controlled by antihistamine drugs, occurs in about 2 per cent. of patients treated with penicillin. The appearance of the serum-sickness-like syndrome 
with angio-oedema is usually delayed for some days while antibodies are being produced, and then urticaria, sometimes of an explosive type with muscle pains and fever, may develop. Occasionally reactions of this type may prove fatal from angio-oedema of the glottis.

(b) Anaphylactic Reactions.-Cases in this group not infrequently prove fatal. Such deaths may occur more frequently in the practitioner's surgery than in hospital, and for this reason command greater attention. Patients in this group may, within a few minutes of injection, develop tingling of the tongue, dry taste in the mouth, weakness, perspiration, palpitations, vertigo, dizziness, oppression, tightness in the chest, pallor or flushing, epigastric pain, nausea, vomiting, visual disturbances, convulsions, incontinence of faeces and/or urine, oedema of the eyelids, or urticaria-alone or in combination. Collapse with cyanosis and a marked fall in blood pressure, laboured respiration, imperceptible pulse, unconsciousness, and death may follow.

Penicillin is the principal offender. Welch, Lewis, Weinstein, and Boeckman (1958) conducted a survey of 827 general American hospitals with a total of 198,332 hospital beds during the 4-year period 1953-1957. Some 1,070 life-threatening reactions were disclosed (penicillin being responsible for 84 per cent.) and also 1,925 non-life-threatening cases of which penicillin was responsible for 83.9 per cent.

There were 809 cases of anaphylaxis, of which 793 had followed the use of penicillin and only sixteen cases had followed the use of streptomycin, chloramphenicol, or the tetracyclines. In 733 cases the penicillin had been given by injection. There were 63 fatalities and all the patients concerned had had penicillin by injection. The incidence of anaphylactoid reactions had increased during each year of the survey. The general fatality rate from anaphylaxis was $9 \cdot 1$ per cent., a considerable improvement on the 28 per cent. noted in an earlier survey (Welch, Lewis, Kerlan, and Putnam, 1953) which perhaps reflects a greater awareness of penicillin anaphylaxis and the more ready availability of resuscitative measures.

The next largest group of life-threatening reactions was that of super-infection, of which there were 107 cases with forty fatalities. Of these, 99 were due to enterocolitis and eight to moniliasis. The tetracyclines were responsible for ninety of the 107 cases concerned.

There were seventy cases of severe skin reactions ( 51 of exfoliative dermatitis, sixteen of purpura, and three of erythema multiforme), seven of which were fatal. 46 of these fatalities followed the use of penicillin. There were 38 life-threatening cases of angiooedema, 37 with severe respiratory involvement and one with cerebral involvement; 37 followed the use of penicillin and one the use of intramuscular chloramphenicol. In five cases in this group the reaction was fatal.

Blood dyscrasias were reported in 46 cases, in 41 of which chloramphenicol had been used alone or in combination. There were 27 fatalities, 25 of which followed the use of chloramphenicol.

It is not surprising that it is the anaphylactic reactions, by their dramatic onset, which excite the most comment. They are certainly increasing in incidence as more and more persons are becoming sensitized to penicillin. In the first 9 years of penicillin usage only two deaths from penicillin sensitivity were recorded in the literature; in 1953 fifteen more deaths had been recorded (Kern and Wimberley, 1953), and by 1954 the number had increased to 48 (Hussar and Holley, 1954). By 1957 it was estimated that 1,000 deaths from penicillin anaphylaxis had occurred in the U.S.A. alone (Peters, Henderson, and Prickman, 1957). Certainly the numbers of deaths have been related to the length of time penicillin has been in use in a particular country (Rajam and Rangiah, 1956).

Anaphylactic reactions are more common in persons who have had penicillin previously than those who have not (for this reason they are uncommon in children), in those with a previous history of allergy (especially asthma), and particularly in those who have previously shewn signs of sensitivity to penicillin. Persons who have had mild anaphylactic symptoms on a previous occasion are very liable to severe anaphylactic shock if penicillin is given again, this emphasizes the importance of carefully noting any mild symptoms like a bad taste in the mouth, nausea, or tinglings when an injection of penicillin has been given. The severity of the anaphylactic reaction is related to the route of administration, few fatal examples having been reported after oral administration. Similarly, the use of slow-release preparations, such as procaine penicillin with aluminium monostearate (PAM), which has been in routine use for many years in V.D. clinics, has probably resulted in relatively few fatalities occurring in such centres. It remains to be seen whether the situation will change now it is proving necessary on the grounds of the increasing resistance of the gonococcus to penicillin to change to the quicker-acting preparations which carry a higher rate of severe allergic reactions. 
Incidence of Allergic Reactions in a V.D. Clinic

If what has been stated strikes a somewhat sombre note it must be emphasized that the incidence of severe reactions, in terms of patients treated and injections of penicillin given, is still very small. A recent World Health Organization Survey, for example, covering 626,551 patients treated with penicillin over a 5 -year period, indicated only nine deaths, or one in 69,600 cases treated (Willcox, $1958 \mathrm{c}$ ). In a survey of over 16,000 patients treated for venereal disease in the U.S.A., Smith, Cutler, and Price (1955) reported that the incidence of anaphylactic reactions was $0 \cdot 2$ per cent. and that no patient had died. Indeed, the relative rarity of untoward penicillin reactions in V.D. clinics is indicated by personal experience in such a clinic near London.

Of 7,300 injections of repository penicillins (penicillin-in-oil beeswax, procaine penicillin with aluminium monostearate, benethamine penicillin, and benzathine penicillin) given to 895 patients over an 11-year period, the over-all incidence of "probable" allergic reactions was 2.9 per cent. of patients and 0.4 per cent. of injections. If all "possible" reactions were included, the figures were 4.8 and 0.6 per cent. respectively (Willcox and Fryers, 1957).

The incidence of reactions was directly related to the number of injections and therefore to the dosage of penicillin. The incidence of reactions was low after single injections but increased with the number of injections up to nine, after which there was an apparent fall. Similar trends were noted as regards dosage, there being no reactions with a dosage of less than one mega unit and a marked fall after twenty injections had been given. The incidence was also noted to increase with the duration of therapy (and therefore with the number of injections) and to be related to previous penicillin administration.

In a venereal disease clinic the reactions tend to be related to diagnosis. Patients with syphilis, who receive many injections of penicillin, have more reactions than patients with gonorrhoea, who usually have but one injection. Similarly there is an apparent relationship with ages, patients with gonorrhoea who have only one injection (and therefore experience few reactions) are young, whereas many of the older patients have many injections (and therefore a greater incidence of reactions) for the treatment of late and latent syphilis, which is relatively less common in the young.

Particularly prone to se sitivity were patients with leg ulceration. in whom thore is a - renter opportunity for sensitization from topical application of penicillin.
One might have expected an increased incidence of reactions with the years, but this has not been the case in this series, if only the "probable" reactions were considered. Similarly, there was no significant difference in the incidence of "probable" reactions between penicillin-in-oil beeswax, procaine penicillin with aluminium monostearate, benzathine penicillin, and benethamine penicillin. Certainly no evidence has so far been forthcoming of unusually prolonged or delayed reactions after the use of long-acting penicillins.

One fatality was noted. This was due to bronchopneumonia complicating dermatitis after penicillinin-oil beeswax. No unequivocal anaphylactoid reaction was observed in the entire series, and the incidence, so far as "probable" reactions were concerned, did not increase through the years.

The above experience comprises about one-third of the author's venereological work during the time under review. No case of anaphylaxis was observed during the same period in the remaining two-thirds of his practice, but three cases of anaphylaxis have been observed more recently, during the past 12 months. None of these was fatal, but their occurrence points to the increasing prevalence of this complication.

\section{Prevention of Penicillin Reactions}

As the incidence of penicillin reactions tends to increase, it is necessary for physicians to do all they can both to reduce their frequency and to minimize their seriousness. Indeed, allergic reactions are already an embarrassment in some parts of the world, where the publicity they have engendered has adversely affected the successful development of campaigns against venereal disease based on the mass use of penicillin. Public opinion requires that physicians should take certain steps. In New York City, for example, where thirty fatal anaphylactic cases have been recorded, nine have been or are subject to law suits (Rosenthal, 1958).

There are four precautions which can be taken:

(1) A careful history of previous allergy, especially to penicillin, should be taken before administering penicillin or other antibiotics;

(2) Skin, ocular, and other tests might be made before giving penicillin;

(3) An emergency kit for the immediate treatment of anaphylactic reactions should always be available:

(4) The indiscriminate ise of antibiotics except on sound therapeutic or prophylactic indications should be discouraged wherever possible. 
(1) History.-The taking of a careful history will reduce appreciably the incidence of allergic reactions. The patient must be asked whether he has had penicillin before, whether any reactions occurred, and whether there is a personal or family history of allergy. Details of the previous administration may be helpful. If the previous dosage was massive and given over a short time, sensitization is less likely to have occurred than if prolonged or frequent courses have previously teen given.

Any side-reactions which have occurred should be noted, not forgetting pruritus, tingling sensations, or slight cardiovascular symptoms. Reactions which occurred immediately or soon after penicillin was given are more important than those which may have occurred some days later.

If a positive history is obtained, other antibiotics or alternative drugs should be given. Penicillin is considered dangerous in asthmatics. There is a need in this respect for an injectable repository tetracycline preparation which will give a useful serum level for $24 \mathrm{hrs}$ after a single injection.

(2) Skin and Other Tests of Sensitivity.-A number of tests designed to determine penicillin sensitivity in a particular patient have been described:

(i) Patch Test.-Linen soaked with penicillin solution is strapped to the skin and the reaction is read after $48 \mathrm{hrs;}$

(ii) Scratch Test.-A drop of crystalline penicillin 10,000 units $/ \mathrm{ml}$. or some penicillin powder with a drop of saline is scratched into the epidermis, giving an immediate result in 10-20 min. and a delayed result after $48 \mathrm{hrs}$;

(iii) Intradermal Test (read at the same times).$0.02 \mathrm{ml}$. penicillin solution of 500 units $/ \mathrm{ml}$. is injected intradermally, increasing the concentration 10 -fold with subsequent tests. If the test is negative a further injection is given using a stronger solution until a solution containing 50,000 units $/ \mathrm{ml}$. is reached;

(iv) Ocular Test.-This may be made by instilling penicillin solution into the eye to see whether it will evoke redness or oedema;

(v) Oral Test.-Penicillin tablets are sometimes given orally as a test dose before injection to see whether it provokes anaphylactic symptoms, less severe than those which would follow an injection of penicillin.

Unfortunately such tests give results which are difficult to interpret. Some patients who may even have previously experienced anaphylaxis do not exhibit a positive skin test, although the immediate intradermal reaction is usually positive in such cases. Moreover, in very sensitive persons, severe allergy may even follow the skin-testing procedure, and fatalities have been known to occur after intradermal tests. Such tests should not be used in persons already known to be penicillin sensitive.

The taking of a test dose of penicillin orally may well reveal the patient who would have developed severe anaphylaxis after an injection of penicillin, and very few fatalities have followed penicillin given orally. It is difficult, however, to adopt any reliable criteria from the pulse rate or from how the patient feels or reacts after such a test dose which a nervous or apprehensive patient might not display through the force of suggestion.

Much has been written concerning the usefulness of preliminary skin-testing, and opinions range from the view that these procedures are of little or no use in predicting anaphylactic sensitivity to a rather reserved support. They are certainly of little value in mass campaigns and are not practical as a routine measure. They may, however, be of use in individual cases (e.g. a case of bacterial endocarditis in which there is a doubtful past history of allergy and in which the use of penicillin, as opposed to other antibiotics, is still considered important).

(3) Treatment of Penicillin Reactions.-For the treatment of urticaria, skin reactions, and angiooedema the withholding of further penicillin administration, the use of antihistamine drugs, and suitable local applications, where necessary, are usually sufficient.

In anaphylaxis, prompt treatment is the essence of success. The fact that, in the two U.S. Hospital Surveys made by Welch and others $(1953,1957)$, the mortality rate from anaphylaxis had been reduced by two-thirds (from 28 to $9 \cdot 1$ per cent.) is indicative of what an awareness of the situation can produce.

It is essential to have always available in clinics and surgeries wherever penicillin is given an emergency kit containing sterile syringes, ampoules of adrenaline (epinephrine) hydrochloride 1:1000, nikethamide, an intramuscularly-given antihistamine drug (e.g. pyribenzamine), an intramuscularlygiven cortisone preparation, aminophyllin for intravenous use, and possibly also penicillinase. It is desirable that oxygen should also be available.

Adrenaline hydrochloride (epinephrine) 1:1000, given subcutaneously in $0 \cdot 5-1-\mathrm{ml}$. doses, is the basis of treatment. Further injections, intravenous if necessary, may be given depending on the state of 
the patient. Benadryl or pyribenzamine $(25-50 \mathrm{mg}$.) should also be given intramuscularly, and in protracted cases cortisone (50-100 mg.). Aminophyllin and oxygen are used when there is respiratory embarrassment.

It may be that penicillinase should also be used. This penicillin-inactivating enzyme is now obtainable commercially in the United States as "Neutrapen". Although there are few reports of its action in anaphylaxis, an intramuscular dose of 800,000 units $(2 \mathrm{ml}$.) has been recommended in this condition (Zimmerman, 1958). Steroids and antihistamine drugs can be used with it to suppress symptoms. No penicillin was detected in the blood 15 to 60 minutes after its use (Becker, 1958); he used it with good results in 48 patients with mainly dermatological reactions, in 24 instances without other drugs. Chen, Bard, Belsito, and Sneig (1958) found Neutrapen lacking in both toxicity and antigenicity, although more recent reports have shewn that penicillinase itself may cause anaphylaxis in susceptible patients. (4) Prevention of Indiscriminate Use of Penicillin.-The antibiotics industry is truly vast. In the U.S.A. in 1956 some seventeen different antibiotics were clinically available, no less than $1,500,000 \mathrm{lb}$. $(681,818 \mathrm{~kg}$.) being produced annually. Penicillin accounted for 38 per cent. of this total, and 121 different penicillin preparations were available. Its dollar value had expanded in only 13 years from zero in 1942 to $\$ 300$ million at the manufacturers' level in 1955 (Welch, 1957). In the British National Health Service the annual cost of antibiotics is in the region of $£ 10,500,000$. The use of antibiotics is fostered by an extensive advertising programme in the journals and in the mail (Figs 1 and 2). As a result, there are few persons who have not at some time had the opportunity to become sensitized to them. In many instances treatment is unnecessary

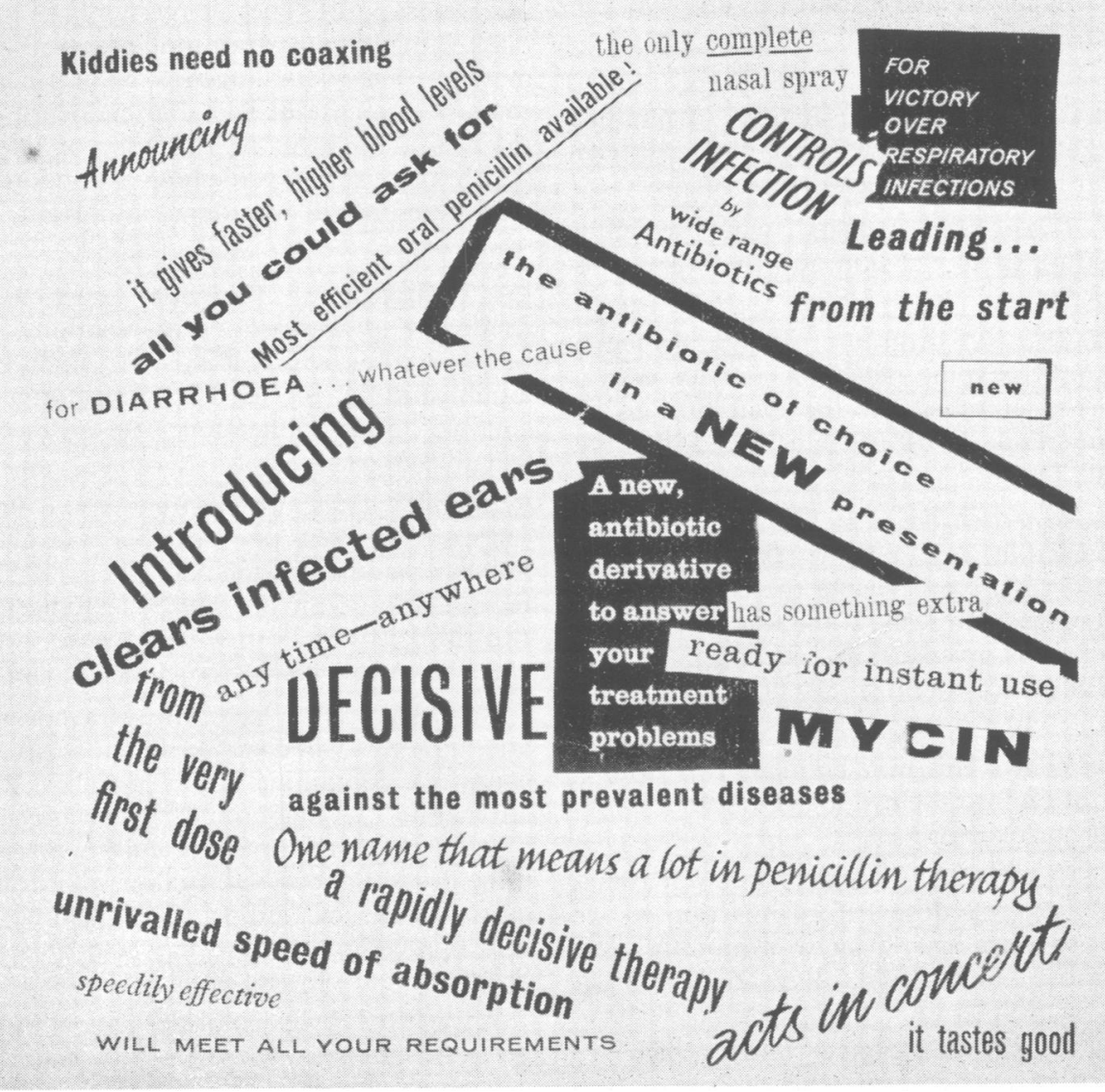

FIG. 1. The advertising of antibiotics to doctors in the U.S.A. 
and antibiotics are sometimes given for trivial and unspecified conditions such as having "tired blood" or being "one degree under". Jawetz (1958) indicated a striking example published by Nolen and Dille (1957) of a very small town (Igloo, North Dakota), with a population of only 793 residents. Only six $(0.76$ per cent.) had failed to receive antibiotics over a 5 -year period. It was calculated that this form of therapy had been unwarranted in more than half of the 2,936 separate illnesses or complaints which had been treated.

Some figures were collected at the end of 1958 concerning antibiotic consumption amongst venereal disease patients. It was not found feasible to collect data on antibiotics other than penicillin. A total of 275 new patients in and around London were studied, 105 females (average age $24 \cdot 3$ years) and 170 males (average age $29 \cdot 5$ years). $57 \cdot 1$ per cent. of females and 76.5 per cent. of males (mean $69 \cdot 1$ per cent.) had received penicillin for some reason during the 5 years before attendance at the V.D. clinic. The incidence of previous reactions was 2.5 per cent. Of those previously exposed to the drug, $48 \cdot 4$ per cent. were given penicillin again. Of those not previously exposed to penicillin, $36 \cdot 5$ per cent. were potentially sensitized by being given it for the first time.

The use of penicillin should be avoided in banal disorders such as the common cold, eczema, impetigo, pharyngitis, and bronchitis, and its topical use should be abandoned altogether. The inclusion of penicillin in tooth-paste, chewing gum, and similar substances is indefensible. Reports of fatal shock cases indicate that about half of the patients who died had received the drug unnecessarily. In one fatal case recorded the condition treated was gynaecomastia-not even an infection (Higgins and Rothchild, 1952).

In many parts of the world the lay public is able to buy antibiotics over the counter without prescription and such practices should be discouraged. Stern warnings seem necessary against the self-medication

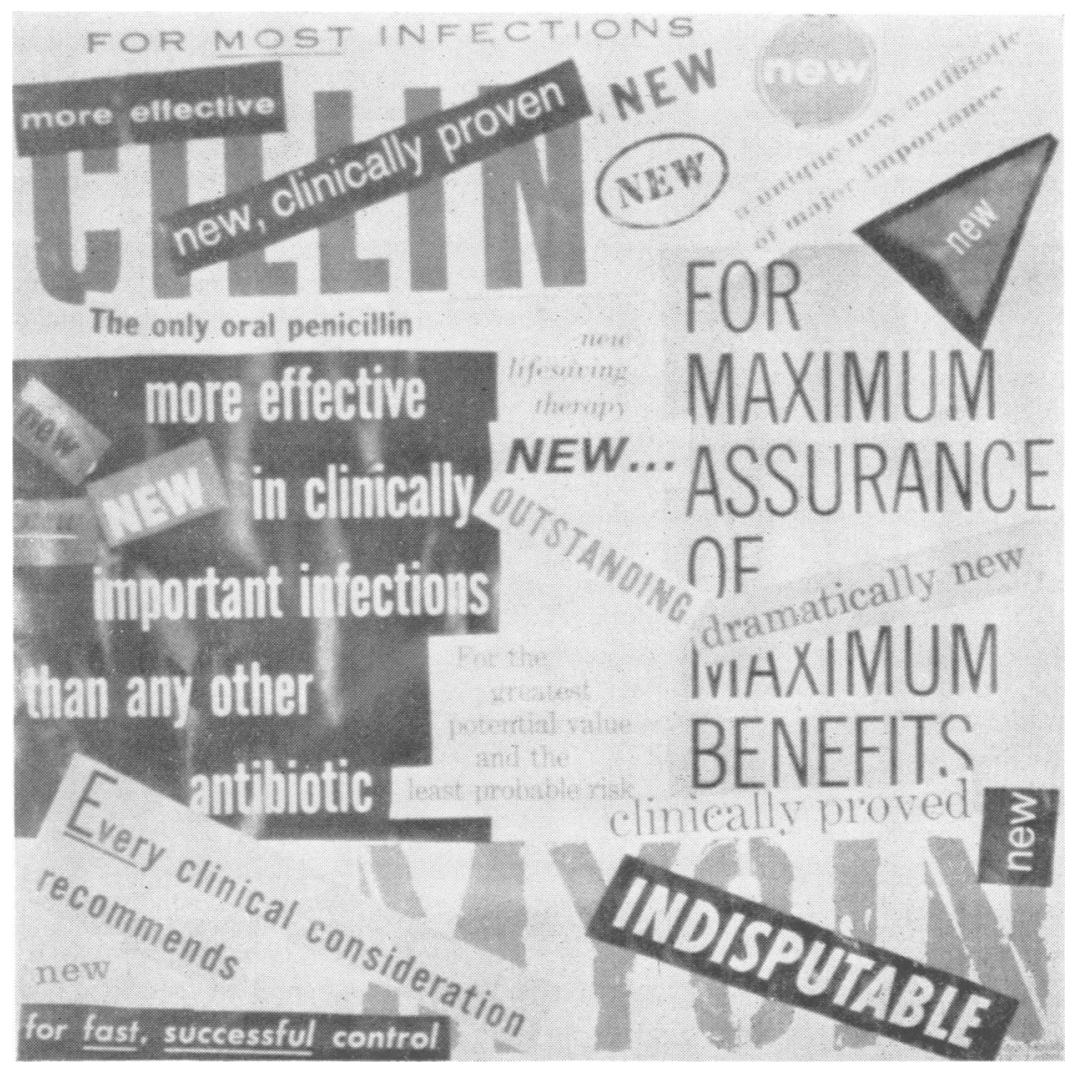

FIG. 2. The advertising of antibiotics to doctors in Great Britain (British Medical Journal and Lancet). 
with antibiotics so frequently used by pharmacists, nurses, and doctors. First-aid "Do it Yourself" antibiotic kits are to te deplored. A number of serious reactions have followed such practices (Siegal, Steinhardt, and Gerber, 1953), and it has been estimated that one in ten of all fatal cases has resulted from self-medication.

Antibiotics are also widely used in agriculture and veterinary medicine, and in the preservation of meat, fish, vegetables, and other products. The possible danger of inducing penicillin sensitivity in consumers must be considered. Recently, for example, Rosenthal (1958) reported that 5.9 to 11.6 per cent. of milk samples in New York City contained from 2 to 80 units penicillin per glass.

Another factor we as physicians must consider is our sterilizers. Coleman and Siegel (1955) shewed that, although the boiling of penicillin induced a rapid fall in antibiotic potency, traces of penicillin could still be detected after 16 hours' boiling. Amounts greater than those found capable of producing antigenic effects have been found in syringes after boiling. It is thus a logical practice to reserve certain syringes, needles, and sterilizing equipment solely for use with penicillin.

\section{Summary and Conclusions}

(1) Reactions to antibiotics may be divided into toxic reactions, microbiogenic sequelae, and allergic reactions.

(2) Systemic toxic reactions are rare after the use of penicillin and the tetracycline antibiotics which are those most frequently used in venereology. Toxic reactions may occur after streptomycin but only very infrequently in the doses used in the treatment of venereal diseases. Chloramphenicol, which may cause blood dyscrasias, is seldom used to-day in this speciality. Local toxic reactions, manifest by pain at the injection site, may follow the use of some of the newer repository penicillins and tetracycline preparations when given by injection.

(3) Among the microbiogenic sequelae are those due to microbial lysis, microbial overgrowth, and microbial resistance.

(4) Two phenomena, due probably to microbial lysis, which occur in the treatment of venereal diseases are therapeutic shock (Herxheimer reaction) and therapeutic paradox.

(5) Microtial overg:owth with antitiotic-resistant organisms is most commonly encountered after the oral administration of antibiotics, staphylococci and monilia being the organisms usually concerned. Super-infection and cross - infection with antibiotic - resistant staphylococci in hospitals are described. Fatal cases of staphylococcal enteritis may sometimes occur when antibiotics are given orally.

(6) The problem of bacterial resistance is currently becoming apparent in venereology in respect of the treatment of gonorrhoea. In spite of increasing doses of penicillin through the years, failure rates of 17 to 30 per cent. are now being encountered with single doses of 1 to 2 mega units of procaine penicillin with aluminium monostearate (PAM) and benzathine penicillin. This has necessitated a change to a shorter-acting penicillin (i.e. aqueous procaine penicillin) capable of ensuring a peak serum level sufficient to overcome the more resistant strains of the gonococcus.

(7) The development of a lessened sensitivity of the gonococcus to penicillin and the greatly increased attack rate of gonorrhoea in a number of the larger cities of the United Kingdom-sufficient to shew as a substantial rise in the national figures-represent a serious public health problem which is likely to increase. It remains to be seen whether the change to aqueous procaine penicillin will also result in an increased attack rate of syphilis or will tend to increase the incidence of more serious allergic reactions.

(8) Allergic reactions consist of skin reactions and anaphylactic reactions. The latter, which are not infrequently fatal, are increasing in incidence in countries where penicillin has been in use longest. In some areas they already constitute an embarrassment to the smooth development of public health programmes and represent a legal hazard for the practitioner. The incidence of serious reactions, however, is still comparatively very low in relation to the enormous amounts of penicillin used. Experiences of 7,300 injections of repository penicillin given over an 11year period in a British V.D. clinic are descrited.

(9) Serious penicillin reactions may be reduced in number by the taking of a careful history of previous allergy, especially to penicillin, and by using another antibiotic when such a 
history is positive. Their seriousness may be reduced by having an emergency kit always available. The contents of such a kit is stated in detail. Skin-testing is not practicable as a routine measure but may be helpful in selected cases.

(10) The most effective method of reducing all reactions to antibiotics is to confine their use to well-tried therapeutic and prophylactic indications. The high degree of "penicillinization" of some countries is noted. Data regarding previous penicillin experience in 275 patients attending a British venereal disease clinic are given.

\section{REFERENCES}

Anderson, R. C., Worth, H. M., Harris, P. N., and Chen, K. K. (1957), "Antibiotics Annual, 1956-1957", ed. H. Welch and F. Marti-Ibañez, p. 75. Medical Encyclopadia, New York.

Beaven, D. W., and Burry, A. F. (1956). Lancet, 2, 211.

Becker, R. M." (1958). "Antibiotics Annual, 1957-1958", p. 310.

Bridges, R. A., Berendes. H., and Good, R. A. (1957). J. Pediat., $50,579$.

Cawthorne, T., and Ranger, D. (1957). Brit. med. J., 1, 1444.

Chen, J. Y. P., Bard, J. W., Belsito, A. A., and Snieg, I. (1958). "Antibiotics Annual, 1957-1958", p. 321.

Coleman, M., and Siegel, B. B. (1955). J. Allergy., 26, 253.

Cradock-Watson, J. E., Shooter, R. A., and Nicol, C. S. (1958) Brit. med.J., 1, i091.

Curtis, F. R., and Wilkinson, A. E. (1958). Brit. J. vener. Dis., 34, 70.

Durel, P. (1958). Personal communication.

Fairlie, C. W., and Kendall, R. E. (1953). J. Amer. med. Ass., 153, 90

Finland, M., and Jones, W. F. (1956). Ann. N.Y. Acad. Sci., 65, art. 3, p. 191.

Gould, J. C. (1958). Lancet, 1, 489.

Guthe, T., Idsöe, O., and Willcox, R. R. (1958). Bull. Wld Hlth Org, $19,427$.
Higgins, G. A., and Rothchild, T. P. E. (1952). New Engl. J. Med., 247, 644 .

Hinton, N. A., and Orr, J. H. (1957). J. Lab. clin. Med., 49, 566.

Hussar, A. E., and Holley, H. E. (1954) "Antibiotics and Antibiotic Therapy: Clinical Manual". New York.

Hwang, K., Primack, N., Stein R. J., and Richards, R. K. (1958). "Antibiotics Annual, 1957-1958”, p. 163.

Jawetz, E. (1958). Ibid., p. 287

Kern, R. A., and Wimberley, N. A. (1953). Amer. J. med. Sci., 226, 357

Knight. G. (1958). Brit. J. vener. Dis., 34, 223.

Laird, S. M. (1958), Brit.J. vener. Dis., 34, 137.

Landman, G. S. Phillips, L. V., and Friend, L. (1958), Sth med. J. (Bgham, Äla), 51, 899.

Ministry of Health (1958). "Report of Chief Medical Officer for the year 1957." Part II. A ppendix C. H.M.S.O., London

Nolen, W. A., and Dille, D. E. (1957). New Engl. J. Med.. 257, 33.

Peters, G. A., Henderson, L. L., and Prickman, L. E. (1957). Ann. Allergy, 15, 135.

Popper, O. (1957). Sth Afr. med. J., 31, 54.

Rajam, R. V., and Rangiah, P. N. (1956). Indian J. med. Sci., 10, 337.

Reyn, A., Korner, B., and Bentzon, M. W. (1958). Brit. J. vener. Dis., 34, 227.

Romansky, M. J., Limson, B. M., and Hawkins, J. E. (1957). “Antibiotics Annual, 1956-1957", p. 706.

Rosenthal, A. (1958). J. Amer. med. Ass., 167, 1118

Rountree, P. M. (1956). Lancet., 1, 719.

Rubin, H. Lehan, P. H., FitzPatrick, M. J., and Furcolow, M. L. (1958). "Antibiotics Annual, 1957-1958", p. 71 .

Schamberg, I. L., Kalodner, A., and Lentz, J. W. (1958). Brit. J. vener. Dis., 34, 24.

Shooter, R. A., Griffiths, J. D., Cook, J., and Williams, R. E. O. (1957). Brit. med. J., 1, 433 .

Siegal, S., Steinhardt, R. W., and Gerber, R. (1953). J. Allergy, 24, 1.

Smith, C. A., Cutler, J. C. and Price E. V. (1955). "Antibiotics Annual, 1954-1955", p. 144.

Streitmann, B., and Krassnigg, A. (1957). Wien. Klin. Wschr., 69, 317.

Thaysen, E. H., Eriksen, K. R., Fischermann, K., and Knudsen, H. E. (1955). Ugeskr. Laeg., 117, 1047.

Welch, H. (1957). "Antibiotics Annual, 1956-1957”, p. 1

-, Lewis, C. N., Kerlan I., and Putnam, L. E. (1953). Antibiot. and Chemother., 3, 891. Cheinstein, H. I., and Boeckman, B. B. (1958). "Antibiotics Annual, 1957-1958", p. 296.

Willcox, R. R. (1958a). Bull Wld Hlth Org., 19, 503.

(1958b). Ibid., 19, 569 .

(1958c)i Ibid., 18, 457.

(1958d). Brit. J., vener. Dis., 34, 205.

and Fryers, G. R. (1957). Ibid., 33, 209.

Zimmerman, M. C. (1958). "Antibiotics Annual, 1957-1958”, p. 312 